\title{
Relationships Between Agronomic and Environmental Soil Test Phosphorus in Three Typical Cultivated Soils in China*1
}

\author{
WANG Xin-Min ${ }^{1,2,3}$, JIE Xiao-Lei ${ }^{1}$, ZHU Yong-Guan ${ }^{2}$, HOU Yan-Lin ${ }^{2}$ and ZHANG Tie-Quan ${ }^{3}$ \\ ${ }^{1}$ Zhengzhou College of Animal Husbandry Engineering, Zhengzhou, Henan 450011 (China). E-mail: kirk123@163.com \\ ${ }^{2}$ Department of Soil Environmental Science, Research Center for Eco-Environmental Sciences, Chinese Academy of Sci- \\ ences, Beijing 100085 (China) \\ ${ }^{3}$ Greenhouse and Processing Crops Research Center, Agriculture \& Agri-Food Canada, Harrow, Ontario NOR 1G (Canada)
}

(Received May 13, 2008; revised September 18, 2008)

\begin{abstract}
A study was conducted to determine the relationships between agronomic soil test $\mathrm{P}$ and environmental soil test $\mathrm{P}$ in three soils predominately distributing in three typical agricultural production areas of China. Soil $\mathrm{P}$ was analyzed using Bray-1 (BP), Olsen (OP), and Mehlich-3 (MP) methods as agronomic tests, and using Fe-oxide impregnated filter paper $(\mathrm{FeP})$, anion-exchange resin membrane (RP), and water (WP) as environmental tests. There were linear relationships between soil $\mathrm{P}$ extractable with all the tests evaluated. The regression coefficients, $R^{2}$, ranged from 0.8164 to 0.9409 between each two of the agronomic soil test $\mathrm{P}$, and ranged from 0.4702 to 0.8990 between each two of the environmental soil test $\mathrm{P}$, when the three soils were considered separately. When soil test $\mathrm{P}$ was analyzed across all the three soils, the highest regression $R^{2}$ was found between OP and MP (0.7940) amongst agronomic soil test P, and between FeP and RP amongst environmental soil test $\mathrm{P}(0.8842)$. While all of the three agronomic soil test $\mathrm{P}$ was linearly related to each of the environmental soil test $\mathrm{P}$ across the three soils, strongest relationships were found between OP and environmental soil test P. Agronomic OP may be adopted as an analytical tool for environmental prediction of soil P.
\end{abstract}

Key Words: environment, phosphorus, testing methods

Citation: Wang, X. M., Jie, X. L., Zhu, Y. G., Hou, Y. L. and Zhang, T. Q. 2008. Relationships between agronomic and environmental soil test phosphorus in three typical cultivated soils in China. Pedosphere. 18(6): 795-800.

\section{INTRODUCTION}

Accumulation of soil phosphorus (P) resulted from long-term continuous application exceeding crop removals has risen concerns with increased loss potential, and consequently the adverse effects on water quality (Sharpley et al., 1996; McDowell and Sharpley, 2001). It is essential to develop an analytical approach that can be used to assess the critical values of $\mathrm{P}$ in runoff or in agricultural soils, based on which beneficial management practices can be developed to minimize non-point sources of $\mathrm{P}$ loss from agricultural land (Shan et al., 2004; Zhang, 2004; Zhang et al., 2005). Traditionally, the methods (Bray 1, Olsen, and Mehlich 3), defined as agronomic soil P tests (Atia and Mallarino, 2002), were all developed with regard to crop production. Some other methods (Fe-oxide impregnated filter paper, anion-exchange resin membrane, and water), defined as environmental soil $\mathrm{P}$ tests, have recently been adopted to predict P loss from farm fields (Atia and Mallarino, 2002; Huang et al., 2004).

Several studies have shown that dissolved P (DP) concentrations in runoff were highly related to soil $\mathrm{P}$ levels that were determined using the agronomical soil tests (Daniel et al., 1994; Sharpley et al., 1994; Kleinman et al., 1999; Cox and Hendricks, 2000). Andraski and Bundy (2003) reported that agronomic soil $\mathrm{P}$ tests, that are already widely available, could provide an adequate indication of DP concentration in runoff, and that specialized environmental soil P tests were usually not necessary. In contrast, Fang et

\footnotetext{
${ }^{* 1}$ Project supported by the National Natural Science Foundation of China (No. 40071053) and Henan Provincial Talents Innovation Foundation, China (No. 0521001700).
} 
al. (2002) found that Bray-1 P was least effective in explaining the availability in runoff DP in calcareous soils. Similar relationships were found by Allen et al. (2006) in five typical USA Midwest soils. Further more, other studies showed that some agronomic soil test $\mathrm{P}$, such as Olsen-P, could not be used alone for prediction of potential $\mathrm{P}$ release, since soils with high $\mathrm{P}$ sorption capacity released less $\mathrm{P}$ than soils with low $\mathrm{P}$ sorption capacity at the same soil test $\mathrm{P}$ level (Torrent and Delgado, 2001). Clearly, the suitability of agronomic soil test $\mathrm{P}$ for environmental prediction varies, depending on the nature of the procedure, soil type and use, and the climatic conditions.

The objective of this study was to determine the relationships between the agronomic and the environmental soil $\mathrm{P}$ tests, which are widely available, in three agricultural soils in China.

\section{MATERIALS AND METHODS}

Site selection and soil sampling

Three soil types, including red earth, fluvo-aquic, and black soil, were selected to represent the soils predominately distributing in three typical agricultural production regions in China. Thirty sites were selected and sampled for each of the red earth, fluvo-aquic, and black soil in Yingtan of Jiangxi Province, Yucheng of Shandong Province, and Gongzhuling of Liaoning Province, respectively. A total of 90 soil samples were collected, for each of them, from 15 to 20 soil cores were extracted at the depth of $0-10 \mathrm{~cm}$ using a stainless steel probe $(5.5 \mathrm{~cm}$ diameter $)$. The soil cores were mixed thoroughly to form a composite sample. The samples were air dried, ground, and passed through a 2-mm sieve prior to laboratory analysis.

\section{Soil analysis}

Selected soil properties were determined using the standard procedures in triplicates (Agrochemistry Committee of Soil Science Society of China, 1984). In brief, soil pH was measured using the potentiometer method; clay content using the pipette method; soil total $\mathrm{P}$ content using the $\mathrm{H}_{2} \mathrm{SO}_{4}-\mathrm{HClO}_{4}$ digestion and molybdenum antimony-ascorbic acid colorimetric method; and organic matter using the external heating and $\mathrm{H}_{2} \mathrm{SO}_{4}-\mathrm{K}_{2} \mathrm{Cr}_{2} \mathrm{O}_{7}$ volumetric method.

Soil $\mathrm{P}$ was analyzed using Bray-1 (BP), Olsen (OP), and Mehlich-3 (MP) methods as agronomic tests, and using Fe-oxide impregnated filter paper (FeP), anion-exchange resin membrane (RP), and water (WP) as environmental tests. The procedures for agronomic soil P tests, FeP, and WP were described by Frank et al. (1998), Menon et al. (1989) and Sharpley (1993), and Pote et al. (1996), respectively.

\section{RESULTS AND DISCUSSION}

\section{Contents of soil test $P$}

The major physical and chemical properties $(0-10 \mathrm{~cm})$ of the three types of soil selected for the study

TABLE I

Major physical and chemical properties $(0-10 \mathrm{~cm})$ of the three types of soil selected for the study

\begin{tabular}{|c|c|c|c|c|c|c|c|}
\hline \multirow[t]{2}{*}{ Location } & \multirow[t]{2}{*}{ Soil type } & \multicolumn{3}{|c|}{ Particle size } & \multirow[t]{2}{*}{ Organic matter } & \multirow[t]{2}{*}{$\mathrm{pH}^{\mathrm{b})}$} & \multirow[t]{2}{*}{ Total P } \\
\hline & & Sand & Silt & Clay & & & \\
\hline & & & $\%$ & & $\mathrm{~g} \mathrm{~kg}^{-1}$ & & $\mathrm{mg} \mathrm{kg}^{-1}$ \\
\hline Yingtan, Jiangxi & Red earth & $40.0 \pm 12^{\mathrm{a})}$ & $34.7 \pm 9$ & $25.3 \pm 8$ & $8.23 \pm 3$ & $5.15 \pm 0.4$ & $358.0 \pm 55.6$ \\
\hline Yucheng, Shandong & Fluvo-aquic soil & $34.5 \pm 9$ & $21.5 \pm 7$ & $44.0 \pm 8$ & $11.6 \pm 5$ & $8.12 \pm 0.3$ & $588.0 \pm 73.8$ \\
\hline Gongzhuling, Jilin & Black soil & $25.1 \pm 10$ & $25.6 \pm 7$ & $49.3 \pm 10$ & $18.5 \pm 5$ & $6.83 \pm 0.6$ & $734.2 \pm 102.0$ \\
\hline
\end{tabular}

a) Means \pm standard deviations.

b) Soil to water ratio of 1:10. 
are shown in Table I. Contents of soil test P extracted using each of the procedures varied remarkably within the 30 sampling sites of each soil type (Table II). The results indicated that the selected sites would have reasonably represented the soil test $\mathrm{P}$ ranges occurring on the farm fields in the three major agricultural production areas in China.

\section{TABLE II}

Contents of soil test $\mathrm{P}(0-10 \mathrm{~cm})$ determined using various extraction methods for the three types of soils selected for the study

\begin{tabular}{|c|c|c|c|c|c|c|c|c|c|}
\hline \multirow{2}{*}{$\begin{array}{l}\text { Soil P test } \\
\operatorname{method}^{\mathrm{a})}\end{array}$} & \multicolumn{3}{|l|}{ Red earth } & \multicolumn{3}{|c|}{ Fluvo-aquic soil } & \multicolumn{3}{|l|}{ Black soil } \\
\hline & Range & Mean & $\mathrm{SD}^{\mathrm{b})}$ & Range & Mean & SD & Range & Mean & $\mathrm{SD}$ \\
\hline & & & & & $\mathrm{kg}^{-1}$ & & & & \\
\hline $\mathrm{BP}$ & $14.4-98.6$ & 32.0 & 12.2 & $7.5-48.5$ & 24.9 & 12.1 & $15.6-82.1$ & 41.4 & 20.4 \\
\hline $\mathrm{OP}$ & $2.1-31.4$ & 7.2 & 1.8 & $5.9-25.7$ & 12.1 & 5.5 & $5.6-28.8$ & 15.7 & 5.4 \\
\hline MP & $14.6-127.7$ & 47.5 & 21.5 & $13.7-112.9$ & 52.8 & 22.3 & $16.2-104.4$ & 62.8 & 24.6 \\
\hline $\mathrm{FeP}$ & $5.6-56.8$ & 22.2 & 8.5 & $9.6-65.4$ & 35.8 & 10.6 & $18.6-95.2$ & 51.0 & 12.5 \\
\hline $\mathrm{RP}$ & $5.8-47.6$ & 24.4 & 2.1 & $10.5-54.2$ & 34.4 & 7.8 & $10.6-89.4$ & 47.9 & 18.6 \\
\hline WP & $0.5-11.8$ & 3.8 & 0.8 & $1.3-10.5$ & 5.6 & 2.2 & $2.4-15.7$ & 6.6 & 3.0 \\
\hline
\end{tabular}

a) $\mathrm{BP}, \mathrm{OP}, \mathrm{MP}, \mathrm{FeP}, \mathrm{RP}$, and WP represent $\mathrm{P}$ extracted using Bray 1, Olsen, Mehlich 3, iron-oxide impregnated filter paper, anion-exchange resin membrane, and water, respectively.

b) Standard deviation.

\section{Correlations between agronomic and environmental soil test $P$}

There were linear relationships between contents of soil test $\mathrm{P}$ extractable using each two of the agronomic soil P tests (Fig. 1). The $R^{2}$ value of the regression between the amounts of BP and MP was higher than those between OP and MP or between OP and BP for the red earth soils. For fluvo-aquic soils, the $R^{2}$ values were largely identical for the regressions of $\mathrm{BP} v s$. MP and OP vs. MP, but slightly increased for OP vs. BP. The $R^{2}$ values of the regressions from the black soils followed the order of OP
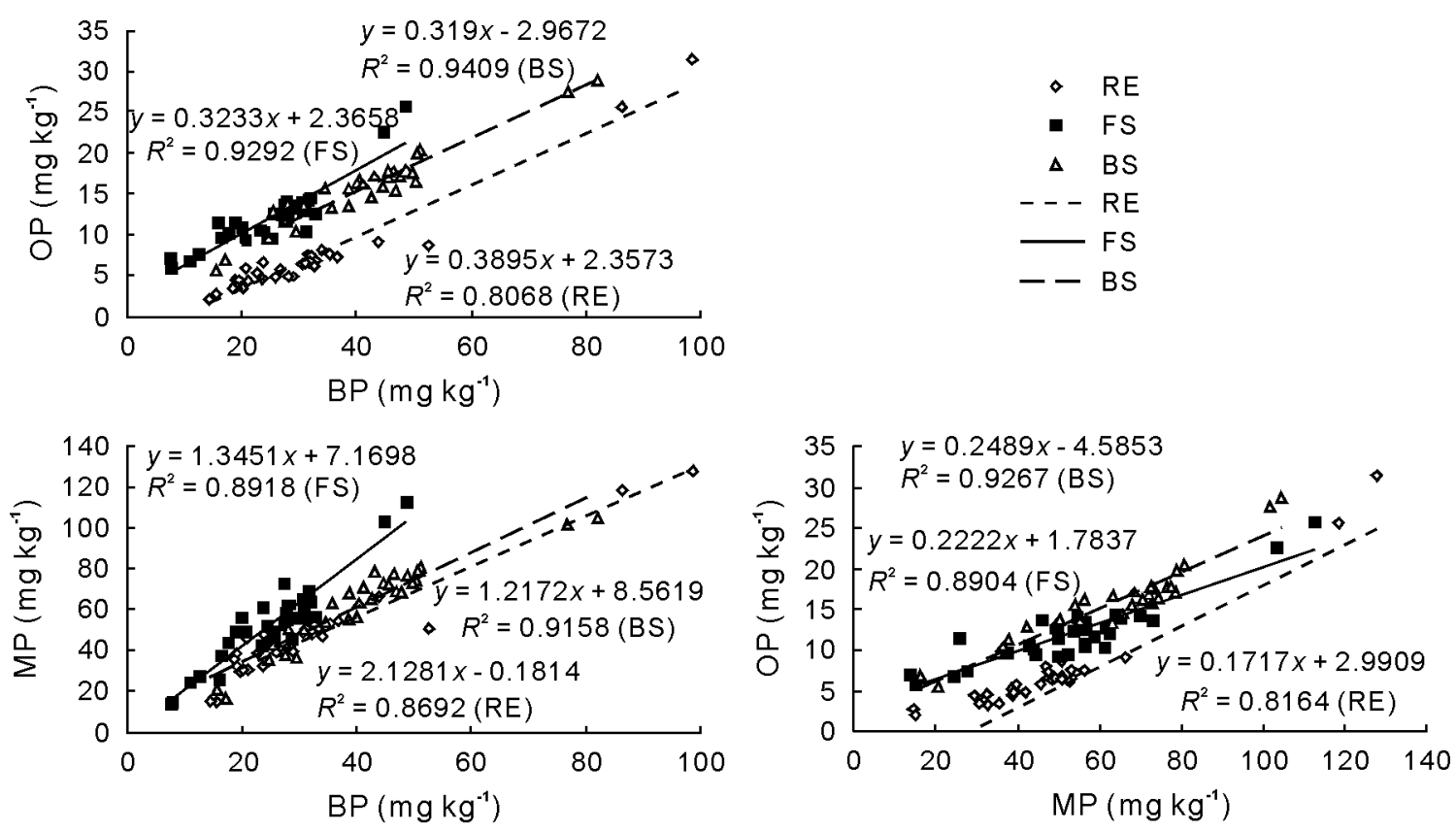

Fig. 1 Relationships between contents of soil test P extractable with Bray-1 (BP), Olsen (OP), and Mehlich-3 (MP) in three soils, including red earth (RE), fluvo-aquic soil (FS), and black soil (BS), predominately distributing in three typical agricultural production areas of China. 
vs. $\mathrm{BP}>\mathrm{OP}$ vs. $\mathrm{MP}>\mathrm{BP}$ vs. $\mathrm{MP}$. An $R^{2}$ value of 0.7940 was obtained for the regression of $\mathrm{OP} v s$. $\mathrm{MP}$ integrating agronomic soil test $\mathrm{P}$ values across all the three types of soil.

While similar relationships to agronomic soil test $\mathrm{P}$ were found for contents of environmental soil test $\mathrm{P}$ determined using each two environmental soil $\mathrm{P}$ tests (Fig. 2), the $R^{2}$ values of the environmental soil test $\mathrm{P}$ regressions were generally smaller than those of the corresponding agronomic soil test $\mathrm{P}$ regressions, when data were analyzed separately for each of the three soil types. However, the $R^{2}$ values of the regression of $\mathrm{FeP}$ vs. RP was largely increased when soil test $\mathrm{P}$ values from all three soil types were considered, with a value as high as 0.8842 obtained. The improved relationships between FeP and $\mathrm{RP}$ was not surprised, as similar sink-based extracting mechanisms were explored with both soil P tests.
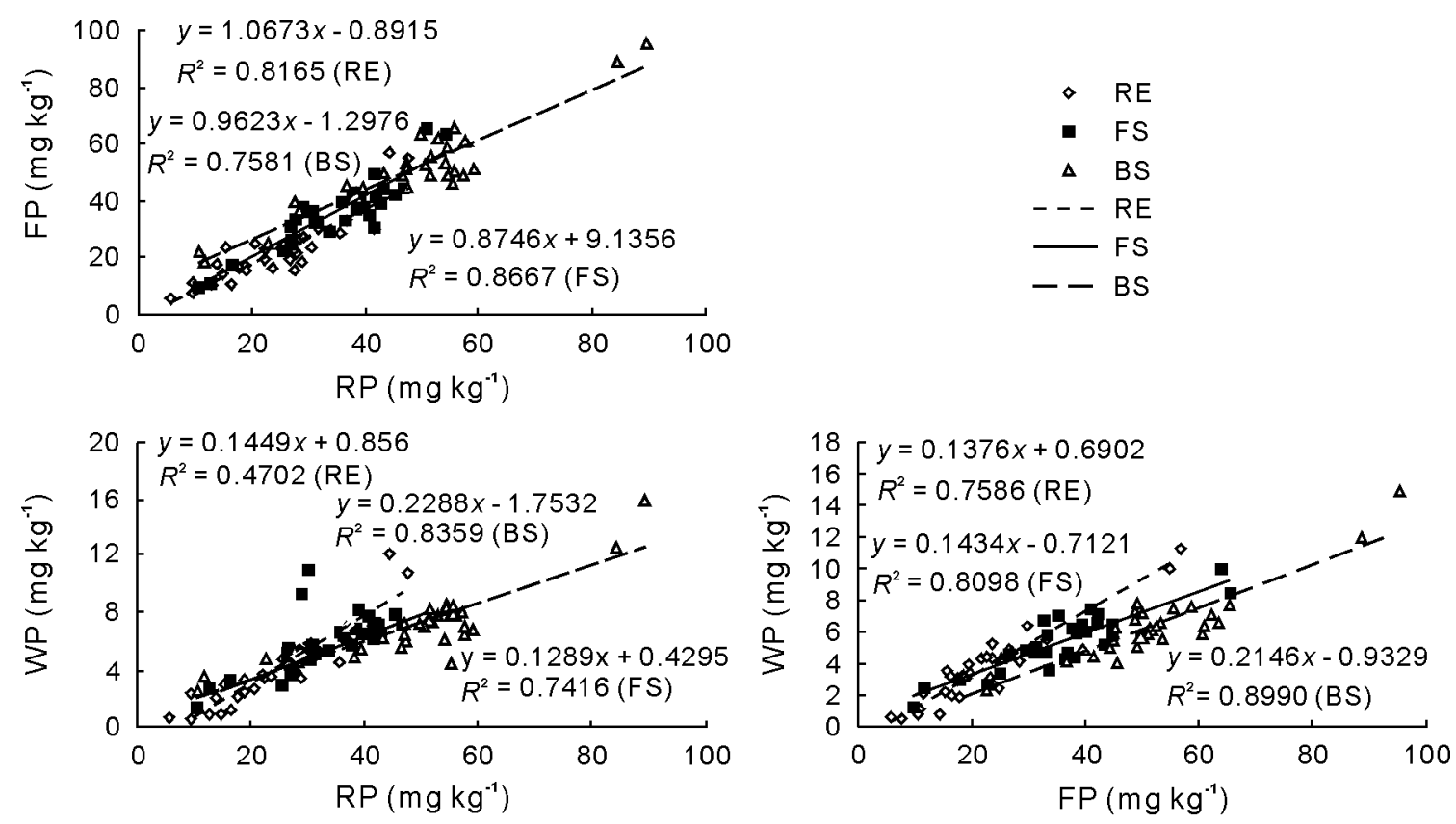

Fig. 2 Relationships between soil test $\mathrm{P}$ extractable with Fe-oxide impregnated filter paper (FeP), anion-exchange resin membrane (RP), and water (WP) for three soils, including red earth (RE), fluvo-aquic soil (FS), and black soil (BS), predominately distributing in three typical agricultural production areas of China.

Contents of environmental soil test $\mathrm{P}$ were linearly related to those of agronomic soil test $\mathrm{P}$ (Fig. 3). The $R^{2}$ value of the regression between FeP and OP was the highest (0.8497), followed by WP vs. OP (0.8106), and RP vs. OP (0.7671), with the one for the regression of FeP vs. BP (0.5866) the lowest. Clearly, OP presented simple but closer relationships with all the environmental soil test $\mathrm{P}$ evaluated in the study, relative to BP and MP. In addition, OP method has long been widely used for prediction of crop available $\mathrm{P}$ in soils of China. Consequently, agronomic OP poses potentials for being adopted for environmental prediction of soil $\mathrm{P}$.

\section{CONCLUSIONS}

Agronomic soil test $\mathrm{P}$ was closely related to environmental soil test $\mathrm{P}$. The strong linear association between them supports the use of agronomic soil test $\mathrm{P}$ data, especially the ones determined using the OP method, in addressing environmental concerns in the three typical agricultural production regions in China. Future studies need to determine the threshold values of agronomic soil test $\mathrm{P}$ for environmental prediction in each individual area, in according to crop type, farming practices, topography, and climatic conditions. 

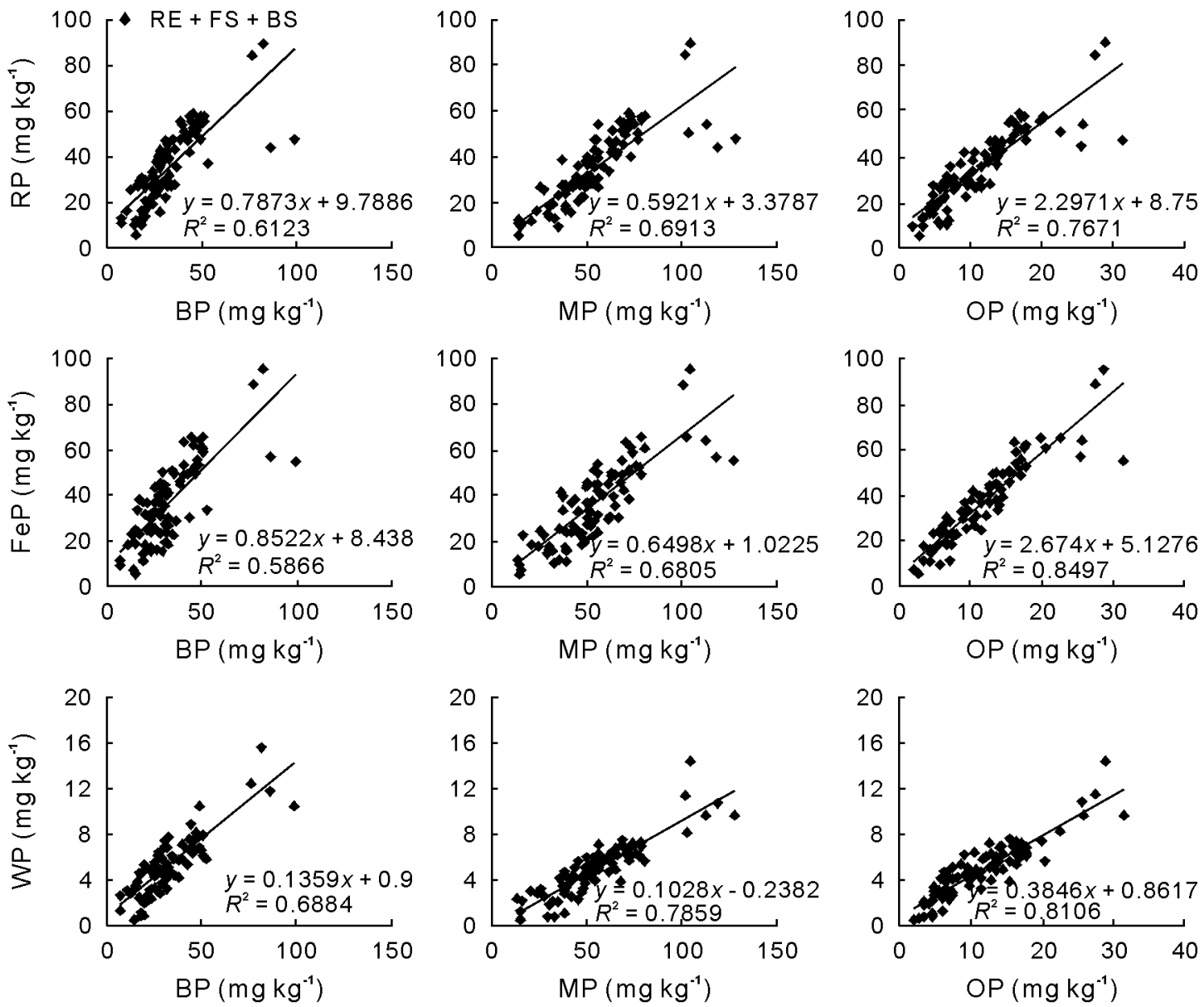

Fig. 3 Relationships between agronomic soil test P (Bray-1, Olsen, and Mehlich-3, with abbreviations of BP, OP, and $\mathrm{MP}$, respectively) and environmental soil test $\mathrm{P}$ (Fe-oxide impregnated filter paper, anion-exchange resin membrane, and water, with abbreviations of FeP, RP, and WP, respectively) across three soil types (red earth, fluvo-aquic soil, and black soil) predominately distributing in three typical agricultural production areas of China.

\section{REFERENCES}

Agrochemistry Committee of Soil Science Society of China. 1984. Methods of Soil and Agrochemistry Convention Analysis (in Chinese). Science Press, Beijing.

Allen, B. L., Mallarino, A. P., Klatt, J. G., Baker, J. L. and Camara, M. 2006. Soil and surface runoff phosphorus relationships for five typical USA Midwest soils. J. Environ. Qual. 35: 599-610.

Andraski, T. W. and Bundy, L. G. 2003. Relationships between phosphorus levels in soil and in runoff from corn production systems. J. Environ. Qual. 32: 310-316.

Atia, A. M. and Mallarino, A. P. 2002. Agronomic and environmental soil phosphorus testing in soils receiving liquid swine manure. Soil Sci. Soc. Am. J. 66: 1696-1705.

Cox, F. R. and Hendricks, S. E. 2000. Soil test phosphorus and clay content effects on runoff water quality. J. Environ. Qual. 29: 1582-1586.

Daniel, T. C., Sharpley, A. N., Edwards, D. R., Wedepohl, R. and Lemunyon, J. L. 1994. Minimizing surface water eutrophication from agriculture by phosphorus management. J. Soil Water Conserv. 49(Suppl.): 30-38.

Fang, F., Brezonik, P. L., Mulla, D. J. and Hatch, L. K. 2002. Estimating runoff phosphorus losses from calcareous soils in the Minnesota River Basin. J. Environ. Qual. 31: 1918-1929.

Frank, K., Beegle, D. and Denning, J. 1998. Phosphorus. In Brown, J. R. (ed.) Recommended Chemical Soil Test Procedures for the North Central Region. North Carolina Regional Research Publication No. 221 (Revised). Missouri Agric. Exp. Stn., Columbia. pp. 21-26.

Kleinman, P. J. A., Bryant, R. B. and Reid, W. S. 1999. Development of pedotransfer functions to quantify phosphorus saturation of agricultural soils. J. Environ. Qual. 28: 2026-2030. 
McDowell, R. W. and Sharpley, A. N. 2001. Soil phosphorus fractions in solution: Influence of fertilizer and manure, filtration and method of determination. Chemosphere. 45: 737-748.

Menon, R. G., Hammond, L. L. and Sissingh, H. A. 1989. Determination of plant available phosphorus by the ironhydroxide impregnated filter paper (Pi) soil test. Soil Sci. Soc. Am. J. 53: 110-115.

Pote, D. H., Daniel, T. C., Sharpley, A. N., Moore Jr., P. A., Edwards, D. R. and Nichols, D. J. 1996. Relating extractable soil phosphorus to phosphorus losses in runoff. Soil Sci. Soc. Am. J. 60: 855-859.

Shan, Y. H., Yang, L. Z. and Wang, J. G. 2004. Soil phosphorus loss to water: Its pathways, environmental impact, and countermeasures. Soils (in Chinese). 36: 602-608.

Sharpley, A. N. 1993. An innovative approach to estimate bioavailable phosphorus in agricultural runoff using iron oxide-impregnated paper. J. Environ. Qual. 22: 597-601.

Sharpley, A. N., Chapra, S. C., Wedepohl, R., Sims, J. T., Daniel, T. C. and Reddy, K. R. 1994. Managing agricultural phosphorus for protection of surface waters: Issues and options. J. Environ. Qual. 23: 437-451.

Sharpley, A. N., Daniel, T. C., Sims, J. T. and Pote, D. H. 1996. Determining environmentally sound phosphorus levels. J. Soil Water Conserv. 51: 160-166.

Torrent, J. and Delgado, A. 2001. Using phosphorus concentration in the soil solution to predict phosphorus desorption to water. J. Environ. Qual. 30: 1829-1835.

Zhang, G. L., Burghardt, W. and Yang, J. L. 2005. Chemical criteria to assess risk of phosphorus leaching from urban soils. Pedosphere. 15: $72-77$.

Zhang, M. K. 2004. Evaluation of phosphorus leachability in sand soils by means of soil P test. Acta Pedol. Sin. (in Chinese). 41: 996-1000. 